\title{
Decreased Hepatic Lactotransferrin Induces Hepatic Steatosis in Chronic Non-Alcoholic Fatty Liver Disease Model
}

\author{
Sungmin Lee Beomseok Son $^{\mathrm{a}}$ Jaewan Jeon ${ }^{\mathrm{a}, \mathrm{b}}$ Gaeul Park ${ }^{\mathrm{a}}$ \\ Hyunwoo Kim ${ }^{a}$ Hyunkoo Kang ${ }^{c}$ HyeSook Youn ${ }^{d}$ Sunmi Job \\ Jie-Young Songe BuHyun Youn ${ }^{\mathrm{a}, \mathrm{c}}$
}

aDepartment of Integrated Biological Science, Pusan National University, Busan, ${ }^{b}$ Department of Radiation Oncology, Haeundae Paik Hospital, Inje University School of Medicine, Busan, 'Department of Biological Sciences, Pusan National University, Busan, dDepartment of Integrative Bioscience and Biotechnology, Sejong University, Seoul, eDivision of Applied Radiation Bioscience, Korea Institute of Radiological \& Medical Sciences, Seoul, Korea

\author{
Key Words \\ NAFLD • Chylomicron • Growth hormone $\cdot$ Coumestrol $•$ Radiation
}

\begin{abstract}
Background/Aims: Non-alcoholic fatty liver disease (NAFLD) is an emerging metabolic disease. Although it leads to severe hepatic diseases including steatohepatitis, cirrhosis, and hepatic cancer, little is known about therapy to prevent and cure hepatic steatosis, the first step of NAFLD. We conducted this investigation to unveil the mechanism of hepatic steatosis. Methods: We established a novel chronic NAFLD mouse model through whole body irradiation and verified the model through histological and biochemical analysis. To find molecular mechanism for hepatic steatosis, we analyzed hepatic transcriptomic profiles in this model and selected target molecule. To induce the expression of lactotransferrin (Ltf) and regulate the NAFLD, growth hormone $(\mathrm{GH})$ and coumestrol was introduced to hepatocyte and mice. The universal effect of coumestrol was confirmed by administration of coumestrol to NAFLD mouse model induced by high-fructose, high-fat, and MCD diet. Results: It was observed that decreased hepatic Ltf expression led to excessive hepatic lipid accumulation in NAFLD mouse. Furthermore, we found that $\mathrm{GH}$ was decreased in irradiated mice and functioned as an upstream regulator of Ltf expression. It was observed that GH could stimulate Ltf expression and prevent uptake of dietary lipids in hepatocytes, leading to rescue of NAFLD. Finally, we suggested that coumestrol, a kind of isoflavonoid, could be used as an inducer of hepatic Ltf expression through cooperation with the $\mathrm{GH}$ signaling pathway both in vitro and in vivo. Conclusions: Hepatic Ltf prevents hepatic steatosis through inhibition of dietary lipid uptake in radiation-induced NAFLD mouse model. We also suggest coumestrol as a drug candidate for prevention of NAFLD.




\section{Introduction}

Non-alcoholic fatty liver disease (NAFLD) refers to be serial diseases derived from excessive accumulation of lipids in the liver. NAFLD reportedly develops from hepatic steatosis to steatohepatitis, liver cirrhosis, and finally a liver cancer [1]. As prevalence of NAFLD was reported to increase to $24 \%$ worldwide, more researches are needed for prevention of NAFLD [2]. Current studies have suggested multiple-hit models for development of NAFLD, which commonly begins from simple accumulation of lipids in liver and develops into excessive oxidative damages derived from increased $\beta$-oxidation of lipids [3]. Because hepatic tissue damage was mainly derived from lipid oxidation, many recent studies have focused on the hepatic injuries and liver carcinogenesis, while there have been few attempts to modulate the initial lipid accumulation [4]. Conversely, some studies emphasized the importance of controlling the initial hepatic steatosis to prevent the fundamental cause of NAFLD and metabolic dysfunctions [5]. In these studies, Sterol regulatory element-binding protein 1c (SREBP-1c), carbohydrate-responsive element-binding protein, acetyl-CoA carboxylase, fatty acid synthase, fatty acid-binding protein, peroxisome proliferator-activated receptor (PPAR) $\alpha$, and PPAR $\gamma$ have been suggested as molecular regulators involved in hepatic steatosis [57]. However, attempts to regulate these metabolic proteins in previous studies did not lead to clinical improvement of NAFLD and the ideal molecular target of hepatic steatosis still remains elusive.

Accumulated hepatic lipids are derived from many sources including de novo lipogenesis, lipoprotein in the blood, and free fatty acid secreted from adipose tissues [8]. Fundamentally, these sources are significantly influenced by dietary lipids, which are digested and absorbed into intestinal cells that synthesize triglyceride (TG), and are then secreted in the form of chylomicron [9]. Chylomicron, a TG-containing lipid particle, is secreted to a lacteal duct, where it is mixed with blood, after which it circulates throughout the body to supply lipid peripheral tissues, including adipose tissues, muscle tissues, and the liver [10]. Because of the role of chylomicron in lipid metabolism, the relationship between chylomicron and induction of hepatic steatosis was investigated in recent studies, which showed regulation of chylomicron uptake significantly improved NAFLD [11,12]. Interestingly, the production of chylomicron was also reportedly regulated by intake of carbohydrate, protein, and even fiber, which emphasizes the universal involvement of chylomicron in metabolism [10]. Therefore, hepatic uptake of chylomicron appears to be the initial regulator of hepatic steatosis and investigation of the development of NAFLD induced by chylomicron uptake could explain the unsolved metabolic dysfunctions in NAFLD studies.

Lactotransferrin (Ltf) is an iron-binding glycoprotein secreted to milk and interstitial fluids and reportedly has various functions including anti-inflammatory, -biotic, -oxidant, -viral and -cancer effects [13]. Furthermore, the administration of Ltf was previously shown to reduce hepatic lipid accumulation and relieve the NAFLD in murine models [13, 14]. Most investigations of the role of Ltf in preventing NAFLD were performed a decade ago and it was discovered that Ltf prevented NAFLD by suppressing chylomicron uptake [15]. Moreover, a structural study explained that Ltf contains an arginine-rich region which was similar to the site of apolipoprotein E (ApoE) binding to low-density lipoprotein receptor (LDLr), LDLr-related protein 1 (LRP-1), or lipolysis-stimulated lipoprotein receptor (LSR) [16]. In the recent study, it was confirmed that Ltf binds to LSR and inhibits chylomicron clearance through ligand blotting experiments [17]. However, the role of hepatic Ltf expression in regulation of NAFLD and the mechanism of Ltf expression regulation still have yet to be elucidated.

The establishment of a proper animal model is important to pre-clinical investigations. In studies to investigate the mechanism of the NAFLD development, many in vivo NAFLD models have been generated by diets including high-fructose, high-fat, and MCD (methionine and choline-deficient) diet or through genetic modification including overexpression of SREBP-1c or silencing PPAR $\alpha$ [18]. Approaches to establish novel NAFLD model have been 
consistently suggested in studies to elucidate molecular mechanism of NAFLD. However, the models commonly showed severe hepatic lipid accumulation within a few days, which is too short to mimic the initial hepatic steatosis of patients even considering the difference in time scale of human and mice [19]. As development of NAFLD spent several months in patients, chronically NAFLD-developing model can show underneath hepatic molecular events in acute models. In addition, using diet-induced NAFLD models could not identify the driving force of NAFLD found in patients without abnormal diet or genetic mutations. Therefore, chronic and diet-independent NAFLD model can overcome the limitation of current NAFLD mouse models.

Among the many causes of NAFLD development, important roles endocrinal disturbance was suggested in current studies. A review summarized that abnormalities of hormones including growth hormone (GH), thyroid hormone (TH), adipokines, and sexual hormones were principally involved in hepatic steatosis and NAFLD [20]. Endocrinal disturbance could be innate, but some studies reported that acquired endocrinal disturbance also led to development of NAFLD as a chronic metabolic disorder. In previous studies, leukemia survivors who were treated with whole body irradiation for stem cell transplantation in childhood developed NAFLD in adulthood [21, 22]. These studies reported that whole body irradiation induced development of NAFLD as a chronic effect (over 10 years) and abnormality of hormones including testosterone, insulin-like growth factor 1, thyroidstimulating hormone, luteinizing hormone, and follicle-stimulating hormone, which was also supported by other previous study [23]. Moreover, endocrine disturbance induced by bisphenol A, a chemical endocrine disruptor, reportedly led to hepatic steatosis [24]. These studies suggested that inducing endocrinal disturbance can be utilized for establishment of NAFLD model. However, the precise molecular mechanism involved in NAFLD development through endocrine disturbance has not yet been completely elucidated.

In this study, we conducted investigation to discover the mechanism of initial hepatic steatosis by establishing a novel NAFLD mouse model with whole body irradiation based on the previous studies. We then analyzed the hepatic transcriptomic profiles, and demonstrated the molecular mechanism of hepatic steatosis.

\section{Materials and Methods}

Cell lines, cultivation and transfection

AML12 (murine normal hepatocyte cell line), MIHA, and HL-7702 (human normal hepatocyte cell lines) were used in the research. AML12 cell line was generously gifted by prof. Heung-Sik Choi (Chonnam National University, Gwangju, Republic of Korea). MIHA cell line was generously gifted by prof. Suk Woo Nam (The Catholic University of Korea, Seoul, Republic of Korea). HL-7702 cell line was generously gifted by prof. Soon-Sun Hong (Inha University School of Medicine, Incheon, Republic of Korea). AML12 was grown in DMEM/F-12, MIHA was grown in DMEM, and HL-7702 was grown in RPMI-1640 containing 10\% FBS, $100 \mathrm{U} / \mathrm{ml}$ penicillin, and $100 \mu \mathrm{g} / \mathrm{ml}$ streptomycin. Cells were incubated in humidified, $95 \%$ air $/ 5 \% \mathrm{CO}_{2}$ atmosphere at $37^{\circ} \mathrm{C}$.

Transient transfection was performed following previous study [25]. Briefly, the mixture of Lipofectamine $^{\mathrm{TM}}$ (Invitrogen, Carlsbad, CA) and pCMV6-Ltf (Origene Technologies, Rockville, MD) was incubated $30 \mathrm{~min}$ for formation of liposome and applied to the MIHA or HL-7702 cells for 12 hours. After exchanging with fresh media, the cells were utilized for further experiments.

\section{Antibodies and reagents}

Primary antibodies specific for Ltf, p-Stat5, Stat5, $\alpha$-tubulin were purchased from Santa Cruz Biotechnology (Santa Cruz, CA). Secondary antibodies specific for mouse IgG, rabbit IgG, and goat IgG were purchased from Enzo Life Sciences (Ann Arbor, MI). Growth hormone (GH) was purchased from Prospec (East Brunswick, NJ) and coumestrol was purchased from Enzo Life Sciences. 


\section{Animal protocol and irradiation}

Animal experiments were performed following previous study [26, 27]. Briefly, 3-week-old male C57BL/6 mice were purchased from Orient Bio Inc. (Busan, Republic of Korea). The animal protocols were approved by the Institutional Animal Care and Use Committee of Pusan National University (Busan, Republic of Korea), and performed in accordance with the provisions of the NIH Guide for the Care and Use of Laboratory Animals. Mice were housed individually or in groups of up to five in sterile cages. Animals were maintained in animal care facilities in a temperature-regulated room $\left(23 \pm 1{ }^{\circ} \mathrm{C}\right)$ under a $12 \mathrm{~h} \mathrm{light} /$ dark cycle, allocated and randomized for the experiments by the technician of the facility, and quarantined for 1 week prior to the study. The animals were fed water and a standard mouse chow diet ad libitum. For animal experiments for generation diet-induced NAFLD mouse model, mice were fed with high-fructose (60\% fructose in weight), high-fat (60\% calorie from fat), or MCD diet.

The mice were anesthetized prior to irradiation and exposed to single irradiation of 6 Gy of gamma-ray generated from Gamma Cell 40 Extractor (Nordion International Inc., Kanata, Ontario, Canada). Irradiated mice were incubated for 5 weeks and intraperitoneally injected with GH ( $2 \mu \mathrm{g} / \mathrm{g} \cdot$ day) or coumestrol $(0.5$ $\mu \mathrm{g} / \mathrm{g} \cdot \mathrm{day}$ ) according to the experiments. The mice were sacrificed after anesthetization and blood and liver were harvested for the analysis following the previous study [28]. The blood was collected from heart, clotted, and serum was isolated through centrifugation $(1500 \mathrm{~g}, 15 \mathrm{~min})$. Serum was frozen in $-70{ }^{\circ} \mathrm{C}$ until further experiments. Liver was cut in $4 \mathrm{~mm}$ thickness and soaked into optimal cutting temperature (OCT) compound (Sakura Finetek, Tokyo, Japan) for histological analysis. Left liver samples were directly frozen in liquid nitrogen, stored in $-70 \stackrel{\circ}{ } \mathrm{C}$ until further experiments.

\section{Histological analysis}

The histological analysis was performed as described in previous study [29]. Frozen block of liver was sectioned in $8 \mu \mathrm{m}$ thickness using Cryostats (Leica Biosystems, Buffalo Grove, IL), dried in room temperature for 1 hour, and stored in $-20{ }^{\circ} \mathrm{C}$. For haematoxylin \& eosin (H\&E) staining, the slides were fixed in formalin solution for $10 \mathrm{~min}$ in RT, and washed in TBS (50 mM Tris-Cl, $150 \mathrm{mM} \mathrm{NaCl}, \mathrm{pH}$ 7.6) for $5 \mathrm{~min}$ twice. The slides were incubated in haematoxylin solution (Muto Pure Chemicals, Tokyo, Japan) for 3 min and washed in distilled water (DW) and blued in $1 \% \mathrm{HCl} 70 \% \mathrm{EtOH}$. Then the slides were moved to eosin solution (Muto Pure Chemicals) and incubated for 5 min and washed in DW for three times. Subsequently dehydration was performed through serial incubation in 70\% EtOH, 95\% EtOH, 100\% EtOH, and xylene. The slides were mounted in Permount Mounting solution (Fisher Scientific, Pittsurgh, PA). The stained slides were visualized by Olympus IX71 fluorescence microscope (Olympus Optical Co. Ltd.).

For Oil Red O (ORO) staining, the slides were fixed in formalin and washed in TBS twice. ORO stock solution (Sigma Aldrich, St. Louis, MO) was diluted in 3:2 with DW to make ORO working solution. The slides were incubated in ORO working solution for $15 \mathrm{~min}$, washed in DW. The slides were counterstained in haematoxylin solution for 3 min and washed, dehydrated, and mounted as described above.

For Sirius red staining, the slides were fixed in formalin and washed in DW twice. Then the slides were incubated in the Sirius red staining solution (0.1\% Direct Red 80 (Sigma Aldrich) solved in picric acid) for 60 min. Then the slides were washed in $0.5 \%$ acetic acid twice, dehydrated, and mounted as described above.

\section{Triglyceride (TG) assay}

The assessment of triglyceride content in liver tissue or hepatocytes were performed following TG assay kit (BioVision, Milpitas, CA). To isolate lipid contents, liver tissue and cells were homogenized and lysed in 5\% NP-40 solution in DW. The lysates were boiled in heat block at $80{ }^{\circ} \mathrm{C}$ for 5 min and cooled at RT for $10 \mathrm{~min}$. This procedure was repeated twice. Subsequently samples were centrifuged at 13, 000 rpm for 2 min and supernatant was obtained. The assessment of TG contents was performed following the manufacturers' instruction and the results were measured by GloMax® Multi Microplate reader (Promega, Madison, WI). For normalization of TG from the liver samples, the content of protein in supernatant was quantified by BioRad protein assay kit (BioRad Laboratories, Hercules, CA) following the previous study [30].

Gene expression profiling and data analysis

The transcriptomic analysis was performed following the previous study [31]. Briefly, total RNA was isolated from liver tissue using RNeasy ${ }^{\circledR}$ (Invitrogen, Carlsbad, CA) and qualified by Nanodrop-1000 
Spectrophotometer (Thermo scientific, Waltham, MA). The RNA was converted to double-stranded cDNA template by IVT (in-vitro transcription), purified using the Affymetrix sample cleanup module, and fragmented using restriction endonuclease. Fragmented cDNA was end-labeled with biotinylated dideoxynucleotide and hybridized to GeneChip ${ }^{\circledR}$ Mouse Gene 2.0 ST arrays. The data was normalized using the Robust Multi-array Average (RMA) algorithm implemented in the Affymetrix Expression Console software (version 1.3.1.) (http://www.affymetrix.com) and signal distributions were compared using plotting using tools obtained from the Bioconductor Project (http://www.bioconductor.org). Differentially expressed genes (DEGs) exhibited > 1.5-fold average signal differences between control and treatment groups were selected. The heat map was depicted through hierarchical clustering method. The result of microarray was deposited in GEO (Accession No. GSE103622)

\section{Semi-quantitative RT-PCR}

To assess the mRNA level in the cell and tissue, semi-quantitative RT-PCR was performed following previous study [32]. The total RNA extracted from liver tissue or hepatocytes were converted to cDNA using SuperScript ${ }^{\circledR}$ VILO cDNA synthesis kit and master mix (Invitrogen, Carlsbad, CA). CDNA was amplified using Taq polymerase (Takara Bio Inc., Tokyo, Japan) following manufacturers' instruction with adequate primers. The primer sequences used for experiments were list below. Mouse Gapdh F: GGT GAA GGT CGG TGT GAA CGG ATT R: GAT GCC AAA GTT GTC ATG GAT GAC C Mouse Ltf F: CGA AGC ACG AAT GAC AAA GA R: ACA AAG CCA ATG GCA GAC TC Human GAPDH F: ATG ACA TCA AGA AGG TGG TG R: CAT ACC AGG AAA TGA GCT TG Human LTF F: GAG AAG GAG TGT TCA GTG GT R: ATA GTG AGT TCG TGG CTG TC

\section{Western blot analysis}

The western blot analysis was performed as described in previously [33]. To prepare the protein sample, the tissue or cells were homogenized and lysed in radioimmunoprecipitation assay (RIPA) lysis buffer (50 mM Tris, $150 \mathrm{mM} \mathrm{NaCl}$ pH 7.4, 1\% Triton X-100, 25 mM NaF, 1 mM dithiothreitol (DTT), 20 mM EGTA, $1 \mathrm{mM} \mathrm{NA}_{3} \mathrm{VO}_{4}, 0.3 \mathrm{mM}$ phenylmethanesulfonyl fluoride (PMSF), and $5 \mathrm{U} / \mathrm{ml}$ aprotinin). Then the lysates were centrifuged by $13,000 \mathrm{rpm}$ at $4{ }^{\circ} \mathrm{C}$ for $15 \mathrm{~min}$. The supernatant were obtained and concentration of total protein was measured by BioRad protein assay kit (BioRad Laboratories). $40 \mu \mathrm{g}$ of protein samples were loaded to SDS-PAGE and transferred to nitrocellulose membrane. The membranes were blocked in $5 \%$ BSA in TBST ( $10 \mathrm{mM}$ Tris, $100 \mathrm{mM} \mathrm{NaCl}$, and $0.1 \%$ Tween 20) for 1 hour at RT and incubated with primary antibodies overnight at $4{ }^{\circ} \mathrm{C}$. Subsequently the membranes were washed in TBST and probed with secondary antibodies for 1 hour at RT and ECL detection system (Roche Applied Science, Indianapolis, IN) was applied to detect.

\section{Enzyme-linked immuosorbent assay (ELISA)}

To assess the levels of serum GH, the serum isolated from blood was used in ELISA following previous study [34]. The obtained blood was incubated $15 \mathrm{~min}$ at RT for clotting and centrifuged for isolation of clots. The supernatant serum was obtained and applied for ELISA. ELISA was performed using GH ELISA kit (USCN Life Science Inc., Houston, TX) following manufacturers' instruction.

\section{Immunofluorescence (IF)}

To assess subcellular localization of Stat5, IF was performed following previous study [35]. Briefly, the cells were seeded in slide glass, treated with GH for $30 \mathrm{~min}$ and fixed with ice cold acetone for $20 \mathrm{~min}$ at -20 ${ }^{\circ} \mathrm{C}$. Then the cells were blocked by $1 \%$ BSA in PBS for 1 hour at RT and incubated with primary antibodies overnight at $4 \stackrel{\circ}{\circ}$. Subsequently the cells were washed and probed with DyLight ${ }^{\circledR} 488$ conjugated secondary antibodies (Thermo Fisher Scientific) and visualized by Olympus IX71 fluorescence microscope.

\section{TG-rich lipoprotein isolation and treatment}

The human plasma for research was purchased from Korean Red Cross (Busan, Republic of Korea). To obtain the TG-rich lipoprotein from the human or murine serum, we performed TG-rich lipoprotein isolation following pervious study [36]. We allocated serum to the polyallomer tube (Beckman Coulter, Pasadena, CA $)$ and placed same volume of $\mathrm{NaCl}(d=1.006 \mathrm{~g} / \mathrm{ml})$ solution on the serum. The tube was centrifuged by ultracentrifuge (Beckman) with SW 40 rotor (Beckman) by 40, $000 \mathrm{rpm}$ for 24 hour at $4{ }^{\circ} \mathrm{C}$. After centrifugation, the upper $10 \%$ of total volume was obtained and the TG contents were measured by TG 
Lee et al.: Decreased Hepatic Lactotransferrin Induces NAFLD

assay kit as described above. In addition, the TG-rich lipoprotein sample was mixed with SDS sample buffer and loaded into SDS-PAGE for silver staining. For the experiments to assess the effect of TG-rich lipoprotein in in vitro model, TG-rich lipoprotein was treated with TG concentration of $0.2 \mathrm{mg} / \mathrm{ml}$ for 24 hours and the TG accumulation was observed through ORO staining or TG assay.

\section{Silver staining}

To confirm the isolation of TG-rich lipoprotein from serum and compare the amount of TG-rich lipoprotein in mouse serum, we performed SDS-PAGE and silver staining as described in previous study [37]. Pierce ${ }^{\mathrm{TM}}$ Silver Stain Kit (Thermo Scientific) was utilized following manufacturers' instruction. In brief, the isolated TG-rich lipoprotein was mixed with SDS sample buffer and loaded into SDS-PAGE. The gels were fixed for $30 \mathrm{~min}$ and washed in DW twice. The sensitizing solution was applied to the gel for $15 \mathrm{~min}$ and stained with silver nitrate solution. Then the gel moved to developing solution for $5 \mathrm{~min}$. The development was stopped, washed, and scanned.

\section{Statistical analysis}

All numeric data are presented as the means \pm standard error (SEM) of at least three independent experiments and sample sizes are calculated to allow significance to be reached. Experimental results were analyzed by one-way ANOVA followed by Tukey's honestly significant difference test, or Student's t-test. Prism 5 software (GraphPad Software, San Diego, CA) was used to conduct statistical analysis, and statistical significance was accepted for $p$-values $<0.05$.

\section{Results}

\section{Establishment of radiation-induced NAFLD mouse model}

To establish chronic NAFLD mouse model, we conducted experiments using whole-body ionizing irradiation to induce NAFLD as previously described [21]. As depicted in Fig. 1A, we designed entire experimental schedules regarding irradiation, incubation, and sacrifice. Based on previous studies stating that patients received radiotherapy in childhood (average 10-year-old) and diagnosed with NAFLD in adulthood (average 25-year-old), we delivered irradiation to mice at the childhood stage and sacrificed mice at the adult stage [21, 22]. Since mice are considered to be juveniles at 3 weeks old and to be mature at 8 weeks old, mice were irradiated at 4 weeks of age and sacrificed at 9 weeks of age [38]. After sacrifice, we found the liver of irradiated mouse to be brown, while that of control mouse was red (Fig. 1B). We also assessed hepatic lipid accumulation of mice through triglyceride quantification assay. As a result, we observed that 9 out of 15 irradiated mice showed more than 1.5-fold increase in hepatic TG amount in comparison with that of control mice (Fig. 1C). According to the histological analysis in Fig. 1D, haematoxylin and eosin (H\&E) staining revealed that more lipid droplets were in the liver of irradiated mice with increased hepatic TG accumulation. We also observed high level of lipid accumulation in liver of irradiated mice with increased hepatic TG accumulation upon Oil Red O (ORO) staining. As radiation induces pro-inflammatory signaling and hepatic inflammation accelerated lipid accumulation in previous study, we performed Sirius red staining to investigate hepatic damages induced by irradiation $[39,40]$. Hepatic fibrosis is usually displayed as accumulation of $\alpha$-smooth muscle actin and results of Sirius red staining revealed that whole body irradiation did not induce significant hepatic fibrosis which was considered to be a damage response after irradiation $[41,42]$. It was also supported by the previous study that ionizing radiation less than 20 Gy did not induce significant normal liver damages [43]. The increased accumulation of hepatic lipids in selected radiation-induced NAFLD mouse livers was verified through assessment of hepatic TG amount (Fig. 1E). Taken together, we validated that whole body irradiation induced hepatic steatosis in mouse model through histological and biochemical analysis of TG accumulation. Furthermore, the result of Sirius Red staining showed that radiationinduced hepatic response did not leads to chronic NAFLD. 
Fig. 1. Establishment of radiation-induced NAFLD mouse model. (A) The schematic description of the experimental schedule. Upper part shows the timing of radiotherapy and diagnosis of patients with whole irradiation therapy following the previous study. The age of patients in each event was converted into that of mice and experiments were performed as depicted in lower part. (B) The livers of control and irradiated mice were photographed. (C) The hepatic TG amount was assessed by TG quantification assay ( $\mathrm{n}=15$ per group). (D) The histological changes were assessed in the liver of control and irradiated mice. (Top) H\&E staining, (middle) ORO staining, and (bottom) Sirius red staining. The scale bar in the H\&E staining and ORO staining indicates $2 \mu \mathrm{m}$ and that in Sirius red staining indicates $5 \mu \mathrm{m}$. (E) The

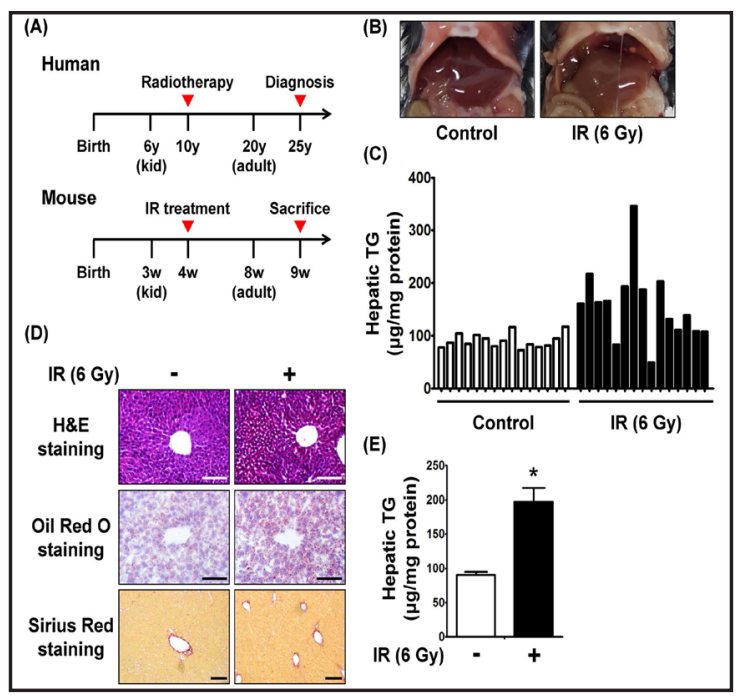
hepatic accumulation of TG was assessed through TG quantification assay ( $\mathrm{n}=5$ per group). Mean \pm SEM. ${ }^{*}, \mathrm{p}<0.05$ compared to the control mice.

Fig. 2. Radiation-induced NAFLD is induced by decreased GH secretion and hepatic Ltf expression. (A) The transcriptional changes of genes with changes $>1.5$-fold in expression were depicted in heat map (271 genes were up-regulated and 184 genes were down-regulated). The genes were rearranged through hierarchical clustering. The position of Ltf in heat map was marked with arrow. (B) The hepatic expression levels of Ltf mRNA in mice were assessed by semi-quantitative RT-PCR. The mRNA expression was quantified from three independent experiments. Mean \pm SEM. *, p $<0.05$ compared to control mice. (C) The

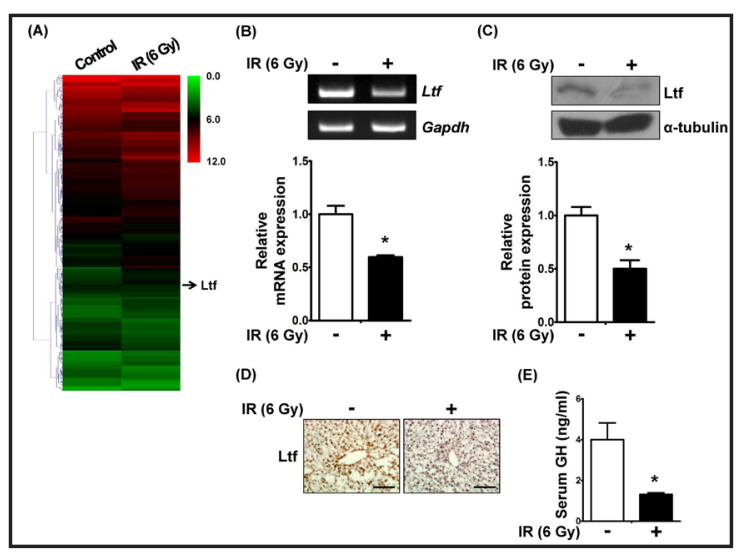
hepatic expression levels of Ltf protein in mice were assessed by Western blot analysis. The protein expression was quantified from three independent experiments. Mean \pm SEM. * , $<0.05$ compared to control mice. (D) The decrease of hepatic expression level of Ltf protein was visualized through IHC. (E) The levels of serum GH in mice were assessed by ELISA ( $\mathrm{n}=5$ per group). Mean \pm SEM. ${ }^{*}, \mathrm{p}<0.05$ compared to control mice.

Radiation-induced NAFLD is induced by decreased GH secretion and hepatic Ltf expression

To investigate the molecular mechanism of radiation-induced NAFLD, we conducted transcriptomic analysis in liver of NAFLD mice (Fig. 2A). Based on the microarray result, we selected target gene among genes whose expression changed by more than 1.5 -fold. As radiation-induced NAFLD was not derived from direct liver damages, we hypothesized that radiation induced damage elsewhere which led to alteration of the hepatic transcript profiles. In previous study, about 2 of 3 cases showed endocrine disturbance after cranial irradiation through damages in secretory glands as a long-term consequence even 20 years after irradiation [44]. Therefore, we attributed hormone as an intermediating regulator of radiation-induced NALFD and screened genes that were reportedly to be regulated by hormones. Firstly, we analyzed ontology with most significant $p$-value-"extracellular region"and searched about the genes in the ontology. "Extracellular region" ontology includes the receptors interacting molecules outside the cells and secreted proteins including protease and fibers. Lactotransferrin (Ltf) was then selected as a candidate for the driving force of the radiation-induced NAFLD. Ltf was reported to be regulated by estrogen, to have inhibitory 
effect on hepatic lipid uptake and to enhance recovery of fatty liver disease [13, 14, 45]. We initially conducted semi-quantitative RT-PCR and Western blot analysis to validate the results of microarray, which revealed that irradiated mice had lower hepatic expression of Ltf (Fig. 2B and 2C). Moreover, decreased Ltf expression in the liver tissue of NAFLD mice was validated through the immunohistochemistry (IHC) (Fig. 2D). Subsequently, we conducted experiment to identify a hormone which regulates hepatic Ltf expression. In a previous study, whole body irradiation reportedly induces malfunctions in the hypothalamic region and reduced GH which is secreted from pituitary gland [23]. The important role of GH in preventing development of NAFLD through the Janus kinase 2 (JAK2)/Signal transducer and activator of transcription 5 (Stat5) pathway was covered in previous study [46]. Therefore, we conducted the experiments to measure the serum GH in the mice and found that irradiated mice showed lower serum GH level than control mice (Fig. 2E). According to these results, we hypothesized that radiation-induced NAFLD was derived from decreased GH, which led to deprivation of hepatic Ltf expression.

\section{Hepatic Ltf expression is modulated by GH signaling pathway}

Based on validation that the serum GH level and expression of Ltf were reduced in irradiated mice, we conducted experiments to investigate whether GH induces Ltf expression in hepatocytes. To accomplish this, we used three hepatocyte cell lines, AML12, MIHA, and HL-7702. AML12 is a murine normal hepatocyte cell line and MIHA and HL-7702 are human normal hepatocyte cell lines. We observed that expression of Ltf mRNA was induced 3 hours after GH treatment (Fig. 3A). As GH is involved in lipid metabolism through Stat5-mediated signaling pathway, we validated activation and nuclear localization of Stat5 upon GH treatment through immunofluorescence (IF) in MIHA cells (Fig. 3B). Western blot analysis demonstrated that GH activated the Stat 5 signaling pathway and increased expression of Ltf

Fig. 3. Hepatic Ltf expression is modulated by $\mathrm{GH}$ signaling pathway. (A) The expression levels of Ltf mRNA in hepatocyte cell lines were assessed by semiquantitative RT-PCR. AML12 is murine hepatocyte cell line and MIHA and HL-7702 are human hepatocyte cell lines. The mRNA expression was quantified from three independent experiments. Mean \pm SEM. ${ }^{*}, \mathrm{p}<0.05$ compared to control cells. (B) The change of subcellular localization of Stat5 in MIHA was visualized by immunofluorescence (IF). The cells were stained after $30 \mathrm{~min}$ of treatment with GH. Nucleus was stained by DAPI (blue) and Stat5 was stained as Green. The scale

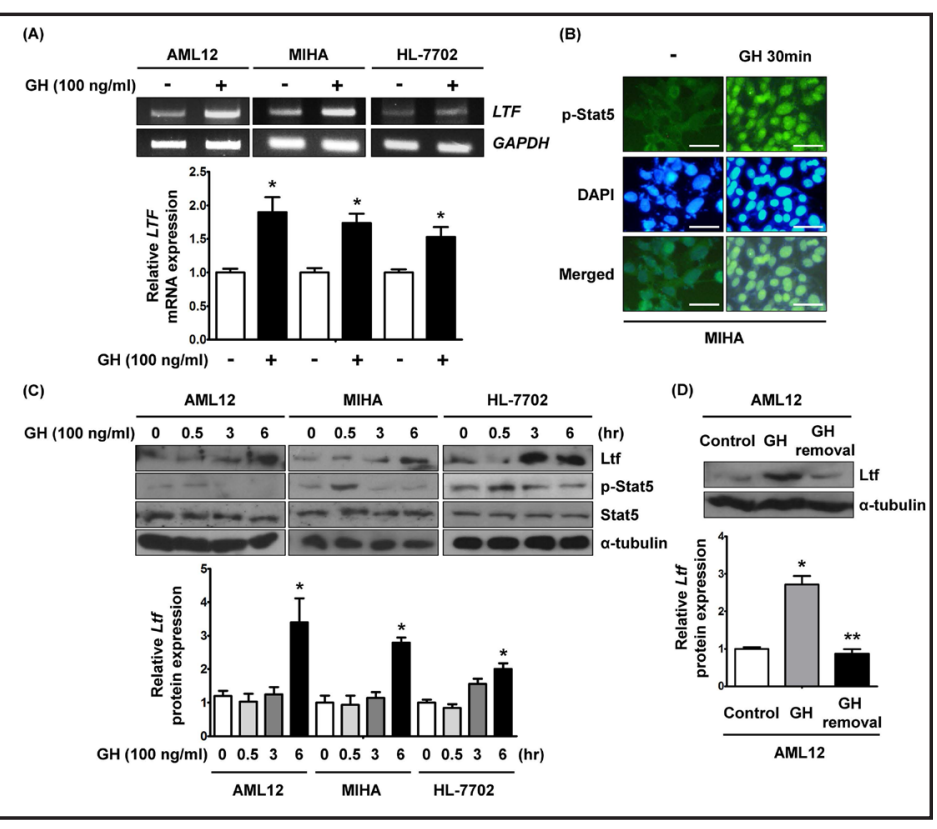
bar indicates $2 \mu \mathrm{m}$. (C) The protein level of Stat 5 was assessed by Western blot analysis in hepatocyte cell lines. The cells were treated with GH for $30 \mathrm{~min}, 3$ hours, or 6 hours. The protein expression was quantified from three independent experiments. Mean \pm SEM. * ${ }^{*}$ p $<0.05$ compared to control cells. (D) The decrease of Ltf by removal of GH was assessed by Western blot analysis. The AML12 cells of GH group were treated with GH for 12 hours twice. The AML12 cells of GH removal group were treated with GH for 12 hours and then media was changed with serum-free media. The protein expression was quantified from three independent experiments. Mean \pm SEM. *, p $<0.05$ compared to control hepatocytes. ${ }^{* *}, \mathrm{p}<0.05$ compared to GH-treated cells.

\section{KARGER}


at least 3 hours after treatment, with peak effects occurring at 6 hours after treatment (Fig. 3C). To strengthen the insight about the relationship between GH and Ltf expression, we conducted extra experiments to verify whether the deprivation of GH could also decrease Ltf expression in an in vitro model. We set control groups by incubation with serum-free media for 24 hours and GH groups by GH treatment at 0 hours and 12 hours. In addition, we set a GH removal group by treatment with GH at 0 hours followed by exchanging to fresh media at 12 hours. The GH removal group showed decreased Ltf expression compared with those in the GH group (Fig, 3D). From these data we confirmed that hepatic Ltf expression is significantly dependent on GH stimulation and that radiation-induced decrease of serum GH and hepatic Ltf could be the driving force of radiation-induced NAFLD.

\section{GH-induced Ltf prevents chylomicron-dependent lipid accumulation}

Ltf has been reported to regulate hepatic lipid uptake through inhibition of interaction between chylomicron and hepatocytes $[17,47]$. To validate the mechanism of GH-induced Ltf in inhibiting hepatic steatosis, we utilized overexpression of human Ltf in an in vitro model and validated through Western blot analysis (Fig. 4A). Subsequently, we isolated TG-rich lipoprotein from human plasma for treatment to the cells and observed TG accumulation in hepatocytes. TG-rich lipoprotein was isolated through density-dependent centrifugation, which was validated through SDS-PAGE and silver staining (Fig. 4B). The fraction with a lower number was the lighter part of the isolates. The results revealed that TG-rich lipoprotein was in lighter part and successfully isolated from other plasma contents, including serum albumin $(70 \mathrm{kDa})$. Moreover, it contains apolipoprotein B48 (ApoB48, 250kDa), a marker protein of chylomicron. The hepatocytes were treated with TG-rich lipoprotein and incubated for 24 hours, after which lipid accumulation was assessed through ORO staining and TG assay. As shown in Fig. 4C, we found that treatment with TG-rich lipoprotein induced lipid accumulation in hepatocytes, which was inhibited by treatment with GH or Ltf overexpression. The result of TG assay also revealed that intracellular TG accumulation increased by $20-30 \%$ upon TG-

Fig. 4. GH-induced Ltf prevents chylomicron-dependent lipid accumulation. (A) The expression levels of Ltf in hepatocyte cell lines upon Ltf overexpression were assessed by Westernblot analysis. The protein expression was quantified from three independent experiments. Mean \pm SEM. *, $\mathrm{p}<0.05$ compared to control cells. (B) The isolation of chylomicron from human plasma was confirmed through silver staining. The fractions were numbered and the lightest was fraction \#1. The ApoB48 (250kDa) was detected as the marker of chylomicron and albumin $(75 \mathrm{kDa})$ was not detected in the isolated TG-rich lipoprotein (fraction \#1).

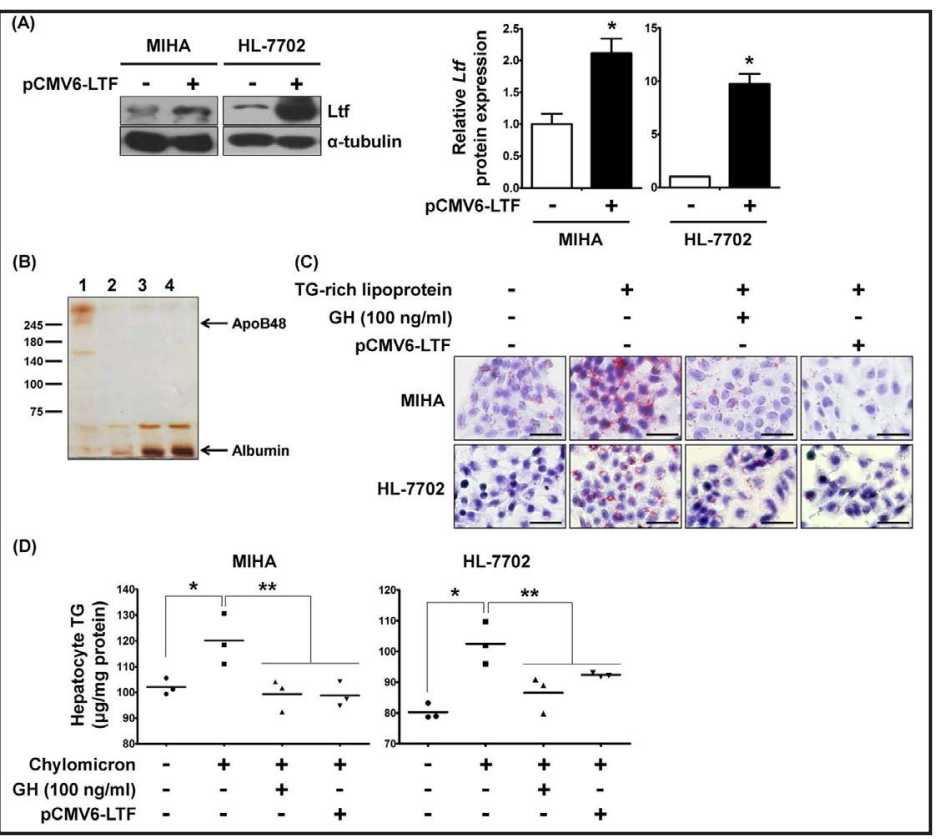
(C) The accumulation of TG in the hepatocyte cell line was visualized by ORO staining. The cells were treated with Ltf overexpression or GH for 12 hours, then incubated with TG-rich lipoprotein for 12 hours, and stained with ORO solution. The scale bar indicates $2 \mu \mathrm{m}$. (D) The accumulation of TG in hepatocytes was assessed by TG assay. The cells were treated as described in $\mathrm{C}$ and TG sample was obtained from the cells. Mean \pm SD. ${ }^{*}, \mathrm{p}<0.05$ compared to control cells. ${ }^{* *}, \mathrm{p}<0.05$ compared to cells with TG-rich lipoprotein. 
rich lipoprotein treatment, which was reduced to that of control cells by treatment with GH or Ltf overexpression (Fig. 4D).

\section{GH and Ltf prevent radiation-induced NAFLD}

Based on the prevention of hepatic steatosis by treatment with $\mathrm{GH}$, we conducted in vivo experiments to validate the mechanism of GH-induced Ltf in inhibition of lipid accumulation. We conducted experiments using mice group treated with both single irradiation and daily $\mathrm{GH}$ administration $(2 \mu \mathrm{g} / \mathrm{g} \cdot$ day $)$. After 5 weeks of incubation, the mice were sacrificed and we measured hepatic alterations. As shown in Fig. 5A, we observed that the injection of GH could not recover the serum GH depletion at all. However, ORO staining revealed that the hepatic lipid accumulation was inhibited in GH-treated mice (Fig. 5B). The result of hepatic TG assay also showed the role of GH in prevention of hepatic steatosis (Fig. 5C). To investigate the involvement of Ltf in prevention of radiation-induced NAFLD in the in vivo mouse model, we analyzed the hepatic expression level of Ltf. The results of IHC for Ltf in Fig. 5B confirmed that liver from GH-treated mice showed up-regulated Ltf expression. We also found that the GHinduced up-regulation of Ltf expression occurred through transcriptional regulation (Fig. 5D and $5 \mathrm{E}$ ). According to the inhibitory role of Ltf in the uptake of chylomicron, we analyzed the chylomicron content in the mouse serum. As shown in Fig. 5F, result of silver staining showed that a higher level of chylomicron remained in the serum of GH-treated mice. Taken together, these findings indicated that administration of GH significantly reduced lipid accumulation through increased hepatic Ltf expression and prevention of hepatic chylomicron uptake.

\section{Coumestrol prevents NAFLD through induction of hepatic Ltf expression}

Although many studies have been conducted to identify the drugs to cure NAFLD, there still has not been a drug with significant efficacy to cure NAFLD [4]. Recent study suggested that NAFLD treatment based on molecular mechanism is needed [48]. In addition, a study suggested natural extract could regulate NAFLD through down-regulation of lipogenic gene expression [49]. In this study, we suggested that coumestrol, a type of isoflavonoid,

Fig. 5. GH and Ltf prevent radiation-induced NAFLD. (A) The serum GH levels of mice were determined through GH ELISA. The mice in GH group were irradiated and daily treated with GH by 2 ug per $g$ of the mice for 5 weeks ( $n=5$ per group). Mean \pm SEM. ${ }^{*}, \mathrm{p}<0.05$ compared to control mice. (B) The hepatic histological changes of the mice treated with GH were determined through ORO staining (upper) and IHC for Ltf (lower). The scale bar indicates $5 \mu \mathrm{m}$. (C) The

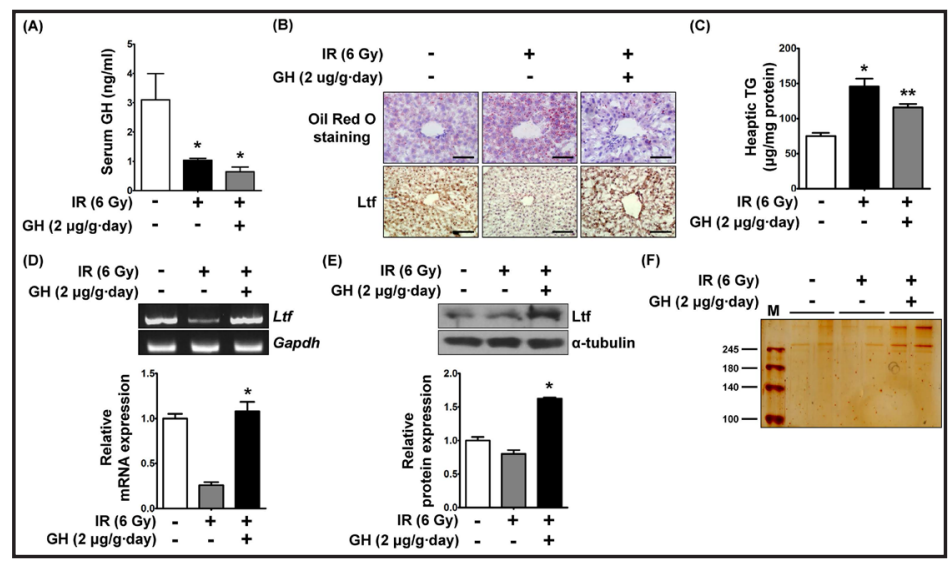
accumulation of TG was assessed by TG assay. Mean \pm SEM. ${ }^{*}, \mathrm{p}<0.05$ compared to control mice ( $\mathrm{n}=5$ per group). ${ }^{* *}, \mathrm{p}<0.05$ compared to irradiated mice. (D) The alteration of hepatic Ltf mRNA expression upon treatment with GH was assessed by semi-quantitative RT-PCR. The mRNA expression was quantified from three independent experiments. Mean \pm SEM. *,$p<0.05$ compared to irradiated mice. (E) The alteration of hepatic Ltf protein expression upon treatment with GH was assessed by Western blot analysis. The protein expression was quantified from three independent experiments. Mean \pm SEM. *, p<0.05 compared to irradiated mice. (F) The changes of serum chylomicron amount were validated by silver staining. The TG-rich lipoprotein was isolated from same amount of serum of the mice and the amount of ApoB48 $(250 \mathrm{kDa})$ was used as a marker for chylomicron. 
could enhance the expression of Ltf (Fig. 6A). According to previous studies, coumestrol could induce Ltf expression in uterine epithelial cells through estrogen receptor activation and active estrogen receptor could stimulate the transcriptional activity of Stat5 [45, 50]. Subsequently, we treated hepatocytes with coumestrol and assessed alteration of Ltf expression. As shown in Fig. 6B, coumestrol could induce Ltf expression, but no synergetic effects between coumestrol and GH treatment were observed in induction of Ltf expression, which referring that the two stimulants converged into single signaling pathway. We next conducted experiments to evaluate the role of coumestrol in inhibition of hepatic lipid accumulation derived from chylomicron. As shown in Fig. 6C, the inhibitory role of coumestrol in hepatic lipid accumulation was observed by ORO staining in both cell lines. This effect was also validated through assessment of intracellular TG accumulation. (Fig. 6D). To validate the in vivo effects of coumestrol, we conducted additional experiments in which mice were treated with single irradiation and daily injection of coumestrol $(0.5 \mu \mathrm{g} / \mathrm{g} \cdot$ day $)$. As shown in Fig. 6E, ORO staining revealed that coumestrol treatment reduced radiationinduced hepatic TG accumulation. The inhibitory role of coumestrol in hepatic steatosis was also validated through TG assay (Fig. 6F). Moreover, we observed that coumestrol treatment induced Ltf expression through transcriptional regulation, which is consistent with those observed in the in vitro experiments (Fig. 6G). Elevated hepatic Ltf expression in mice treated with coumestrol was shown in result of IHC (Fig. 6E). In summary, coumestrol induced Ltf expression in harmony with GH signaling both in the in vitro and in vivo model and prevented development of NAFLD through inhibition of the uptake of dietary fat.

Fig. 6. Coumestrol prevents NAFLD through induction of hepatic Ltf expression. (A) The molecular structure of coumestrol. (B) The alteration of Ltf protein expression upon treatment with GH or coumestrol was assessed by Western blot analysis. The protein expression was quantified from three independent experiments. Mean \pm SEM. ${ }^{*}, \mathrm{p}<0.05$ compared to control cells. (C) The accumulation of TG in the hepatocyte cell line was visualized by ORO staining. The cells were treated with GH or coumestrol for 12 hours, then incubated with TG-rich lipoprotein for 12 hours, and stained with ORO solution. The scale bar indicates

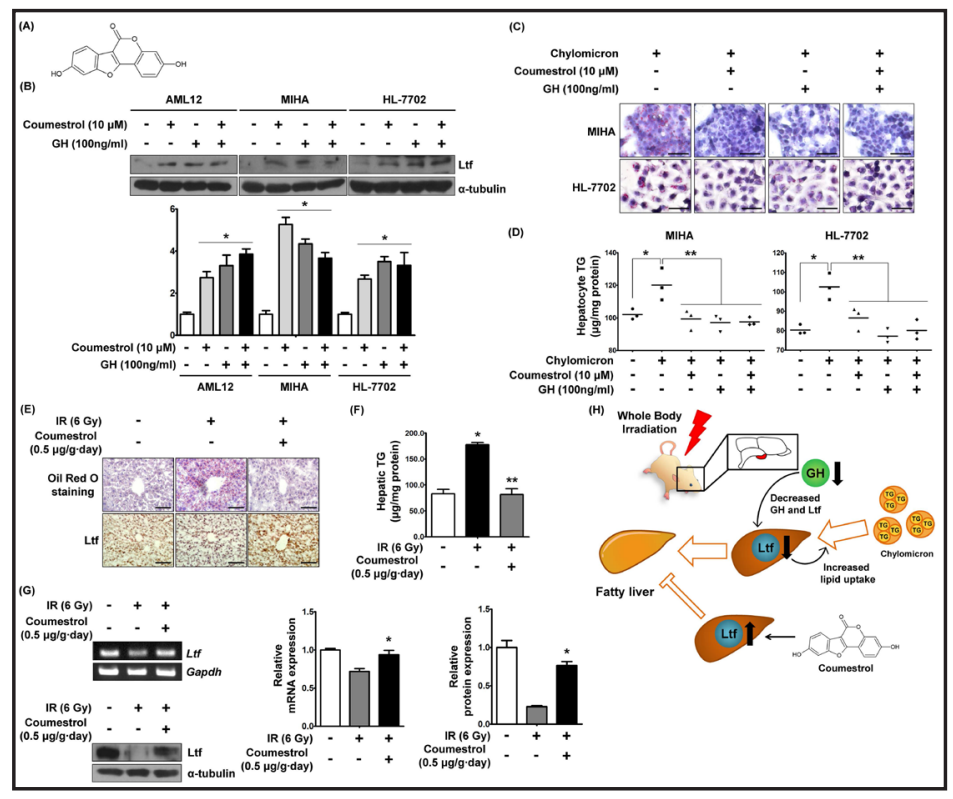
$2 \mu \mathrm{m}$. (D) The accumulation of TG

was assessed by TG assay. Mean \pm SD. ${ }^{*}, \mathrm{p}<0.05$ compared to control cells. ${ }^{* *}, \mathrm{p}<0.05$ compared to cells with TG-rich lipoprotein. (E) The hepatic histological changes of the mice treated with coumestrol were determined through ORO staining (upper) and IHC for Ltf (lower). The scale bar indicates $5 \mu \mathrm{m}$. (F) The alteration of hepatic TG accumulation was assessed by TG assay. The mice were irradiated and daily treated with coumestrol by $0.5 \mu \mathrm{g} / \mathrm{g}$ for 5 weeks ( $\mathrm{n}=5$ per group). Mean \pm SEM. ${ }^{*}, \mathrm{p}<0.05$ compared to control mice. **, $\mathrm{p}<0.05$ compared to irradiated mice. (G) The alteration of hepatic Ltf mRNA and protein expression upon treatment with coumestrol was assessed by semi-quantitative RT-PCR and Western blot analysis. The mRNA and protein expression was quantified from three independent experiments. Mean \pm SEM. *, p $<0.05$ compared to irradiated mice. $(\mathrm{H}) \mathrm{A}$ diagram illustrated the pathogenesis of radiation-induced NAFLD and recovery of hepatic steatosis through treatment of coumestrol. 


\section{Coumestrol prevents development of diet-induced NAFLD}

Based on the effects of coumestrol in prevention and cure of NAFLD, we conducted experiments with several NAFLD mouse models induced by diet (high-fructose, high-fat, and MCD diet) to investigate the general application of coumestrol to regulate NAFLD. We adopted these models because the excessive consumption of carbohydrate or fat and deficiency of methionine and choline were widely known to be principal cause for development of NAFLD [51]. As shown in Fig. 7A, 7B, and 7C, each diet induced hepatic steatosis and the assessment of hepatic TG accumulation supported the increased hepatic lipid accumulations. In response to treatment with coumestrol, diet-induced hepatic steatosis was ameliorated in mice which received high-fructose and high-fat diet. However, mice that received the MCD diet did not show significant changes in their hepatic lipid content upon treatment with coumestrol, because the pathogenesis caused by the MCD diet was independent on lipid uptake. Interestingly, we also found that administration of coumestrol could reduce body weight only in mice that received the high-fat diet (Fig. 7D). In addition, we found that diet and treatment of coumestrol did not alter serum GH level (Fig. 7E). As for the Ltf expression, we observed that diet did not reduced hepatic Ltf expression as presented in radiation-induced

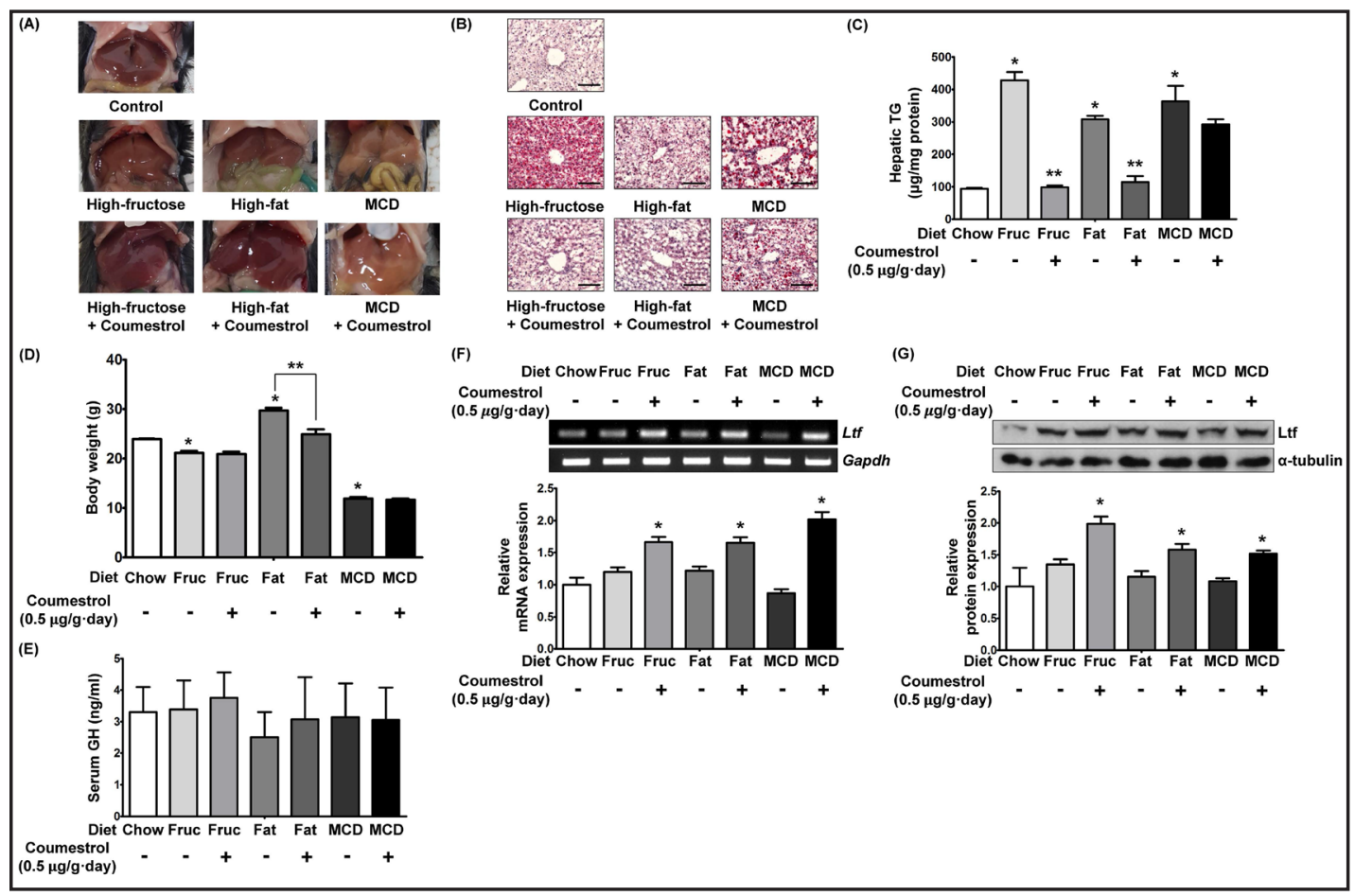

Fig. 7. Coumestrol prevents development of diet-induced NAFLD. (A) The liver of mice which received high-fructose, -fat, or MCD diet and coumestrol was photographed. (B) The alteration of hepatic steatosis was visualized through ORO staining. The mice received each diet and coumestrol $(0.5 \mu \mathrm{g} / \mathrm{g})$ for 5 weeks and sacrificed. The scale bar indicates $5 \mu \mathrm{m}$. (C) The alteration of hepatic TG accumulation was assessed by TG assay ( $\mathrm{n}=5$ per group). Mean \pm SEM. ${ }^{*}, \mathrm{p}<0.05$ compared to control mice. ${ }^{* *}, \mathrm{p}<0.05$ compared to diet-only treated mice. (D) The body weight of mice with high-fructose, -fat, or MCD diet and coumestrol were measured ( $\mathrm{n}=5$ per group). Mean \pm SEM. ${ }^{*}, \mathrm{p}<0.05$ compared to control mice. ${ }^{* *}, \mathrm{p}<0.05$ compared to mice with high-fat diet. (E) The serum GH levels of mice were determined through GH ELISA $(n=5$ per group). Mean \pm SEM. (F) The alteration of hepatic Ltf mRNA expression upon treatment with coumestrol was assessed by semi-quantitative RT-PCR. The mRNA expression was quantified from three independent experiments. Mean \pm SEM. *, $\mathrm{p}<0.05$ compared to diet-only treated mice. (G) The alteration of hepatic Ltf protein expression upon treatment with coumestrol was assessed by Western blot analysis. Mean \pm SEM. The protein expression was quantified from three independent experiments. ${ }^{*}, \mathrm{p}<0.05$ compared to dietonly treated mice. 
NAFLD mouse model and coumestrol treatment significantly increased Ltf expression in liver (Fig. 7F and 7G). Taken together, the regulatory role of coumestrol and Ltf expression on lipid uptake can prevent development of NALFD induced by high-fructose and high-fat diet.

\section{Discussion}

In this study, we established a novel chronic NAFLD mouse model through irradiation to young mice and investigated the molecular biomarker involved in hepatic steatosis, an initial step of the NAFLD. Through analysis of transcriptomic profiles, we found that depletion of hepatic Ltf expression led to hepatic lipid uptake and that GH was an upstream regulator of Ltf expression. We experimentally confirmed that GH induced Ltf expression through the Stat5 signaling pathway using in vitro and in vivo models. Furthermore, Ltf regulated lipid uptake through preventing chylomicron uptake of hepatocytes. Coumestrol was utilized to induce Ltf expression and inhibit the development of NAFLD in hepatocytes. The overall investigation of this study was summarized in Fig. 6F. These findings provided basic information regarding the initial hepatic steatosis under normal diet conditions and suggest a potential molecular target for treatment of the NAFLD.

The fundamental driving force of hepatic steatosis has not discovered yet, however, a deeper understanding of NAFLD pathogenesis can lead to development of a completely curative treatment. In this context, many studies utilized diet-induced NAFLD models which were generated by an excessive uptake of certain nutrient. However, the models had some limitations in that they could not fully mimic the NAFLD patients and they showed highly acute responses [18]. In addition, the molecular mechanisms underlying each NAFLD model differed from each other, leading to confusion regarding NAFLD pathogenesis. For example, hepatic ketohexokinase $C$ was increased and caused NAFLD in mice that received highfructose diet, but was not in mice that received high-fat diet [52]. Another study reported a significant difference in transcriptomic profiles between mice fed with high-fructose and high-fat diets [53]. We also observed these differences among the models in our research (Fig. 7). Based on our findings, we suggested hormone disturbance as an important underlying driving force of NAFLD pathogenesis instead of the special diet. Previous studies also suggested that TH, estrogen, and GH were related to NAFLD and played roles in regulation of hepatic steatosis $[16,46,54]$. The results of these studies supported the present study in that they demonstrated the important role of hormones regulation in development of NAFLD. Therefore, we suggest that the radiation-induced NAFLD mouse model can serve as a novel chronic NAFLD model based on hormone disturbance and that it can be utilized for further studies without using special diet.

In the context of regulation of Ltf expression, only estrogen and prolactin were suggested as inducers of Ltf in previous studies $[45,55]$. Although the organs expressing Ltf were reported to be very limited in the past, a recent study newly reported that the liver expressed Ltf upon pro-inflammatory stimulation and that Ltf was involved in the liver immune system [56]. Nevertheless, the molecular mechanism of hepatic Ltf expression still has been elusive. In this study, we investigated the involvement of hormone in Ltf regulation based on the postirradiation hormone abnormality and found that GH was a potential regulator of hepatic Ltf expression. A weak evidence of the involvement of GH in Ltf expression was previously suggested by the study reporting that prolactin is a member of the GH family and that shares binding affinity with that of GH [57]. In addition, it was reported that GH can activate prolactin receptor and GH receptor by direct binding, and that the signaling transductions of activated receptors converged on the Stat5 pathway [57,58]. Moreover, the binding site for Stat5 (TTC(T/C)N(G/A)GAA) was reportedly present in the promoter of the Ltf gene in cow and pig $[59,60]$. Based on this information, we also validated this relationship between Stat 5 and Ltf expression in humans through analysis of the promoter sequence of Ltf. From -585bp to $-576 \mathrm{bp}$ in the upstream of the first exon of Ltf, a binding site for Stat5 (TTCTTAGAA) was found. Although the binding site for estrogen receptor was not found in the promoter of the 
Ltf gene, a previous study suggested there was a physical interaction between Stat 5 and estrogen receptor, which explained the involvement of estrogen receptor in expression of Stat5-responsive genes [50]. Furthermore, a previous study stating that farnesoid X receptor mediates estrogen receptor activation also supported the cooperative activation of estrogen receptor upon coumestrol treatment [61]. Taken together, the GH- and coumestrol-induced Ltf expression was consistent with the previous studies and we confirmed their role in Ltf expression through in vitro and in vivo experiments.

The regulation of dietary lipid uptake has been suggested as a promising therapeutic strategy for metabolic diseases including NAFLD, diabetes, and obesity. A recent review suggested the molecular targets involved in TG-lich lipoproteins as novel therapeutic targets for NAFLD [62]. In this study, we found Ltf to be an inhibitor of hepatic lipid uptake and validated its function in both in vitro and in vivo models. The potentiality for utilizing Ltf as a therapeutic strategy can be supported by many previous studies covering the molecular mechanism of the Ltf. It was suggested that Ltf competitively inhibits the interaction between LRP-1, heparan sulfate proteoglycan (HSPG), and ApoE, which begins endocytosis of the chylomicron [47]. Specifically, Ltf was an interaction partner of LRP-1 and reduced the chance of recognizing ApoE, which is responsible for chylomicron uptake by hepatocyte. Previous studies covering the molecular mechanisms of these proteins further strengthen the importance of Ltf. A LRP-1 knock-out mouse model reportedly lost almost all chylomicron uptake and HSPG knock-down hepatocytes also showed depleted chylomicron uptake [63, 64]. Therefore, we inferred that the involvement of Ltf in chylomicron uptake significantly influences hepatic steatosis and this study suggested that inducing hepatic Ltf expression could be used to effectively treat NAFLD.

The incidence of NAFLD has been increasing and one fifth of people are suffered from NAFLD worldwide because of an absence of drugs with significant pharmacological effects. In the present study, we investigated canonical pathways that can induce NAFLD through radiation-induced chronic NAFLD mouse models. Transcriptomic analysis showed that depletion of GH and hepatic Ltf expression in irradiated mice was an inducing factor of NAFLD. Moreover, we investigated whether the natural compound coumestrol could overcome NAFLD. The results of the present study suggest that the modulation of hepatic dietary fat uptake can be a promising target and that the function of Ltf can provide insight into the development of drugs for NAFLD.

\section{Acknowledgements}

This research was supported by Basic Science Research Program through the National Research Foundation of Korea (NRF) funded by the Ministry of Education (2017R1D1A1B03028769) and supported by a grant of the Korea Institute of Radiological and Medical Sciences (KIRAMS), funded by Ministry of Science, ICT and Future Planning, Republic of Korea (1711045557;1711045538;1711045554).

Biospecimens were used in the preliminary study for this research and the biospecimens and data used for this study were provided by the Biobank of Ajou University Hospital, a member of Korea Biobank Network.

We thank Prof. Heung-Sik Choi, Prof. Suk Woo Nam, and Prof. Soon-Sun Hong for their generous gift of cell lines.

\section{Disclosure Statement}

The authors declare that no conflict of interests exists. 


\section{Cellular Physiology Cell Physiol Biochem 2018;47:2233-2249 \begin{tabular}{l|l} 
and Biochemistry Published online: July 05, 2018 & $\begin{array}{l}\text { C } 2018 \text { The Author(s). Published by S. Karger AG, Basel } \\
\text { www.karger.com/cpb }\end{array}$ \\
\hline
\end{tabular}}

\section{References}

1 Ibrahim SH, Hirsova P, Malhi H, Gores GJ: Animal Models of Nonalcoholic Steatohepatitis: Eat, Delete, and Inflame. Dig Dis Sci 2016;61:1325-1336.

-2 Satapathy SK, Sanyal AJ: Epidemiology and Natural History of Nonalcoholic Fatty Liver Disease. Semin Liver Dis 2015;35:221-235.

3 Buzzetti E, Pinzani M, Tsochatzis EA: The multiple-hit pathogenesis of non-alcoholic fatty liver disease (NAFLD). Metabolism 2016;65:1038-1048.

4 Rinella ME, Sanyal AJ: Management of NAFLD: a stage-based approach. Nat Rev Gastroenterol Hepatol 2016;13:196-205.

-5 Ferramosca A, Zara V: Modulation of hepatic steatosis by dietary fatty acids. World J Gastroenterol 2014;20:1746-1755. Liss KH, Finck BN: PPARs and nonalcoholic fatty liver disease. Biochimie 2017;136:65-74.

Wu Y, Zhu YB, Huang R, Peng X, Lin X: Multiple MicroRNAs Ameliorate Hepatocyte Steatosis and Injury by Suppressing FABP1 Expression. Cell Physiol Biochem 2017;44:2243-2255.

8 Koo SH: Nonalcoholic fatty liver disease: molecular mechanisms for the hepatic steatosis. Clin Mol Hepatol 2013;19:210-215.

-9 Schwenger KJ, Allard JP: Clinical approaches to non-alcoholic fatty liver disease. World J Gastroenterol 2014;20:1712-1723.

10 Dash S, Xiao C, Morgantini C, Lewis GF: New Insights into the Regulation of Chylomicron Production. Annu Rev Nutr 2015;35:265-294.

-11 Nass KJ, van den Berg EH, Faber KN, Schreuder T, Blokzijl H, Dullaart RPF: High prevalence of apolipoprotein B dyslipoproteinemias in non-alcoholic fatty liver disease: The lifelines cohort study. Metabolism 2017;72:37-46.

12 Farr S, Taher J, Adeli K: Glucagon-like peptide-1 as a key regulator of lipid and lipoprotein metabolism in fasting and postprandial states. Cardiovasc Hematol Disord Drug Targets 2014;14:126-136.

13 Morishita S, Ono T, Fujisaki C, Ishihara Y, Murakoshi M, Kato H, Hosokawa M, Miyashita K, Sugiyama K, Nishino H: Bovine lactoferrin reduces visceral fat and liver triglycerides in ICR mice. J Oleo Sci 2013;62:97103.

14 Mortimer BC, Beveridge DJ, Martins IJ, Redgrave TG: Intracellular localization and metabolism of chylomicron remnants in the livers of low density lipoprotein receptor-deficient mice and apoEdeficient mice. Evidence for slow metabolism via an alternative apoE-dependent pathway. J Biol Chem 1995;270:28767-28776.

15 Chang S, Maeda N, Borensztajn J: The role of lipoprotein lipase and apoprotein E in the recognition of chylomicrons and chylomicron remnants by cultured isolated mouse hepatocytes. Biochem J 1996;318 ( Pt 1):29-34.

-16 Gutierrez-Grobe Y, Ponciano-Rodriguez G, Ramos MH, Uribe M, Mendez-Sanchez N: Prevalence of non alcoholic fatty liver disease in premenopausal, posmenopausal and polycystic ovary syndrome women. The role of estrogens. Ann Hepatol 2010;9:402-409.

17 Ahmad N, Girardet JM, Akbar S, Lanhers MC, Paris C, Yen FT, Corbier C: Lactoferrin and its hydrolysate bind directly to the oleate-activated form of the lipolysis stimulated lipoprotein receptor. FEBS J 2012;279:43614373.

-18 Imajo K, Yoneda M, Kessoku T, Ogawa Y, Maeda S, Sumida Y, Hyogo H, Eguchi Y, Wada K, Nakajima A: Rodent models of nonalcoholic fatty liver disease/nonalcoholic steatohepatitis. Int J Mol Sci 2013;14:2183321857.

19 Zhang YK, Yeager RL, Tanaka Y, Klaassen CD: Enhanced expression of Nrf2 in mice attenuates the fatty liver produced by a methionine- and choline-deficient diet. Toxicol Appl Pharmacol 2010;245:326-334.

20 Marino L, Jornayvaz FR: Endocrine causes of nonalcoholic fatty liver disease. World J Gastroenterol 2015;21:11053-11076.

21 Hyodo H, Ishiguro H, Tomita Y, Takakura H, Koike T, Shimizu T, Morimoto T, Yabe H, Yabe M, Kojima S, Shiraishi K, Minemura T, Kato S: Decreased serum testosterone levels in long-term adult survivors with fatty liver after childhood stem cell transplantation. Biol Blood Marrow Transplant 2012;18:1119-1127. 


\section{Cellular Physiology Cell Physiol Biochem 2018;47:2233-2249

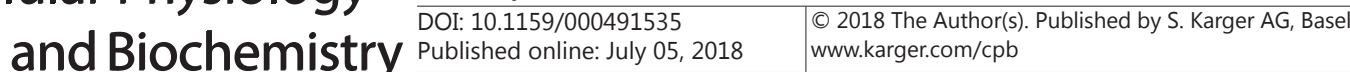

22 Tomita Y, Ishiguro H, Yasuda Y, Hyodo H, Koike T, Shimizu T, Morimoto T, Hattori K, Matsumoto M, Inoue H, Yabe H, Yabe M, Shinohara O, Kojima S, Minemura T, Kato S: High incidence of fatty liver and insulin resistance in long-term adult survivors of childhood SCT. Bone Marrow Transplant 2011;46:416-425.

-23 Darzy KH: Radiation-induced hypopituitarism. Curr Opin Endocrinol Diabetes Obes 2013;20:342-353.

-24 Tarantino G, Valentino R, Di Somma C, D’Esposito V, Passaretti F, Pizza G, Brancato V, Orio F, Formisano P, Colao A, Savastano S: Bisphenol A in polycystic ovary syndrome and its association with liver-spleen axis. Clin Endocrinol (Oxf) 2013;78:447-453.

-25 Kim E, Youn H, Kwon T, Son B, Kang J, Yang HJ, Seong KM, Kim W, Youn B: PAK1 tyrosine phosphorylation is required to induce epithelial-mesenchymal transition and radioresistance in lung cancer cells. Cancer Res 2014;74:5520-5531.

26 Kwon T, Youn H, Son B, Kim D, Seong KM, Park S, Kim W, Youn B: DANGER is involved in high glucoseinduced radioresistance through inhibiting DAPK-mediated anoikis in non-small cell lung cancer. Oncotarget 2016;7:7193-7206.

27 Wang L, Zhang N, Wang Z, Ai D, Cao Z, Pan H: Decreased MiR-155 Level in the Peripheral Blood of NonAlcoholic Fatty Liver Disease Patients may Serve as a Biomarker and may Influence LXR Activity. Cell Physiol Biochem 2016;39:2239-2248.

28 Lou Y, Chen YD, Sun FR, Shi JP, Song Y, Yang J: Potential Regulators Driving the Transition in Nonalcoholic Fatty Liver Disease: a Stage-Based View. Cell Physiol Biochem 2017;41:239-251.

29 Kim W, Kim E, Lee S, Kim D, Chun J, Park KH, Youn H, Youn B: TFAP2C-mediated upregulation of TGFBR1 promotes lung tumorigenesis and epithelial-mesenchymal transition. Exp Mol Med 2016;48:e273.

30 Wu G, Rui C, Chen J, Sho E, Zhan S, Yuan X, Ding Y: MicroRNA-122 Inhibits Lipid Droplet Formation and Hepatic Triglyceride Accumulation via Yin Yang 1 Cell Physiol Biochem 2017;44:1651-1664.

-31 Kang J, Kim W, Lee S, Kwon D, Chun J, Son B, Kim E, Lee JM, Youn H, Youn B: TFAP2C promotes lung tumorigenesis and aggressiveness through miR-183- and miR-33a-mediated cell cycle regulation. Oncogene 2017;36:1585-1596.

-32 Son B, Jun SY, Seo H, Youn H, Yang HJ, Kim W, Kim HK, Kang C, Youn B: Inhibitory effect of traditional oriental medicine-derived monoamine oxidase B inhibitor on radioresistance of non-small cell lung cancer. Sci Rep 2016;6:21986.

-33 Kim W, Youn H, Kang C, Youn B: Inflammation-induced radioresistance is mediated by ROS-dependent inactivation of protein phosphatase 1 in non-small cell lung cancer cells. Apoptosis 2015;20:1242-1252.

34 Kim W, Kim E, Yang HJ, Kwon T, Han S, Lee S, Youn H, Jung Y, Kang C, Youn B: Inhibition of hedgehog signalling attenuates UVB-induced skin photoageing. Exp Dermatol 2015;24:611-617.

35 Youn H, Son B, Kim W, Jun SY, Lee JS, Lee JM, Kang C, Kim J, Youn B: Dissociation of MIF-rpS3 complex and sequential NF-kappaB activation is involved in IR-induced metastatic conversion of NSCLC. J Cell Biochem 2015;116:2504-2516.

-36 Manning PJ, Jong SA, Ryalls AR, Sutherland WH: Paraoxonase 1 activity in chylomicrons and VLDL: the effect of type 2 diabetes and meals rich in saturated fat and oleic acid. Lipids 2012;47:259-267.

-37 Kang J, Kim W, Kwon T, Youn H, Kim JS, Youn B: Plasminogen activator inhibitor-1 enhances radioresistance and aggressiveness of non-small cell lung cancer cells. Oncotarget 2016;7:23961-23974.

-38 Vinhas M, Araujo AC, Ribeiro S, Rosario LB, Belo JA: Transthoracic echocardiography reference values in juvenile and adult 129/Sv mice. Cardiovasc Ultrasound 2013;11:12.

39 Fukunishi S, Sujishi T, Takeshita A, Ohama H, Tsuchimoto Y, Asai A, Tsuda Y, Higuchi K: Lipopolysaccharides accelerate hepatic steatosis in the development of nonalcoholic fatty liver disease in Zucker rats. J Clin Biochem Nutr 2014;54:39-44.

-40 Yang HJ, Youn H, Seong KM, Yun YJ, Kim W, Kim YH, Lee JY, Kim CS, Jin YW, Youn B: Psoralidin, a dual inhibitor of COX-2 and 5-LOX, regulates ionizing radiation (IR)-induced pulmonary inflammation. Biochem Pharmacol 2011;82:524-534.

41 Cheng W, Xiao L, Ainiwaer A, Wang Y, Wu G, Mao R, Yang Y, Bao Y: Molecular responses of radiation-induced liver damage in rats. Mol Med Rep 2015;11:2592-2600.

42 Al Fadel F, Fayyaz S, Japtok L, Kleuser B: Involvement of Sphingosine 1-Phosphate in Palmitate-Induced Non-Alcoholic Fatty Liver Disease. Cell Physiol Biochem 2016;40:1637-1645.

43 Bolling T, Willich N, Ernst I: Late effects of abdominal irradiation in children: a review of the literature. Anticancer Res 2010;30:227-231. 


\section{Cellular Physiology Cell Physiol Biochem 2018;47:2233-2249 \begin{tabular}{l|l} 
and Biochemistry Published online: July 05, 2018 & $\begin{array}{l}\text { (c) } 2018 \text { The Author(s). Published by S. Karger AG, Basel } \\
\text { www.karger.com/cpb }\end{array}$ \\
\hline
\end{tabular}}

44 Appelman-Dijkstra NM, Kokshoorn NE, Dekkers OM, Neelis KJ, Biermasz NR, Romijn JA, Smit JW, Pereira AM: Pituitary dysfunction in adult patients after cranial radiotherapy: systematic review and metaanalysis. J Clin Endocrinol Metab 2011;96:2330-2340.

45 Jefferson WN, Padilla-Banks E, Clark G, Newbold RR: Assessing estrogenic activity of phytochemicals using transcriptional activation and immature mouse uterotrophic responses. J Chromatogr B Analyt Technol Biomed Life Sci 2002;777:179-189.

46 Sos BC, Harris C, Nordstrom SM, Tran JL, Balazs M, Caplazi P, Febbraio M, Applegate MA, Wagner KU, Weiss EJ: Abrogation of growth hormone secretion rescues fatty liver in mice with hepatocyte-specific deletion of JAK2 J Clin Invest 2011;121:1412-1423.

-47 Lillis AP, Van Duyn LB, Murphy-Ullrich JE, Strickland DK: LDL receptor-related protein 1: unique tissuespecific functions revealed by selective gene knockout studies. Physiol Rev 2008;88:887-918.

$\checkmark 48$ Charytoniuk T, Drygalski K, Konstantynowicz-Nowicka K, Berk K, Chabowski A: Alternative treatment methods attenuate the development of NAFLD: A review of resveratrol molecular mechanisms and clinical trials. Nutrition 2017;34:108-117.

49 Zeng L, Tang W, Yin J, Feng L, Li Y, Yao X, Zhou B: Alisol A 24-Acetate Prevents Hepatic Steatosis and Metabolic Disorders in HepG2 Cells. Cell Physiol Biochem 2016;40:453-464.

50 Wang Y, Cheng CH: ERalpha and STAT5a cross-talk: interaction through C-terminal portions of the proteins decreases STAT5a phosphorylation, nuclear translocation and DNA-binding. FEBS Lett 2004;572:238-244.

-51 Abd Elwahab AH, Ramadan BK, Schaalan MF, Tolba AM: A Novel Role of SIRT1/ FGF-21 in Taurine Protection Against Cafeteria Diet-Induced Steatohepatitis in Rats. Cell Physiol Biochem 2017;43:644-659.

52 Ishimoto T, Lanaspa MA, Rivard CJ, Roncal-Jimenez CA, Orlicky DJ, Cicerchi C, McMahan RH, Abdelmalek MF, Rosen HR, Jackman MR, MacLean PS, Diggle CP, Asipu A, Inaba S, Kosugi T, Sato W, Maruyama S, SanchezLozada LG, Sautin YY, Hill JO, Bonthron DT, Johnson RJ: High-fat and high-sucrose (western) diet induces steatohepatitis that is dependent on fructokinase. Hepatology 2013;58:1632-1643.

53 Huang JP, Cheng ML, Hung CY, Wang CH, Hsieh PS, Shiao MS, Chen JK, Li DE, Hung LM: Docosapentaenoic acid and docosahexaenoic acid are positively associated with insulin sensitivity in rats fed high-fat and high-fructose diets. J Diabetes 2017;9:936-946

54 Eshraghian A, Hamidian Jahromi A: Non-alcoholic fatty liver disease and thyroid dysfunction: a systematic review. World J Gastroenterol 2014;20:8102-8109.

55 Nakajima K, Nakamura M, Gao XD, Kozakai T: Possible involvement of prolactin in the synthesis of lactoferrin in bovine mammary epithelial cells. Biosci Biotechnol Biochem 2008;72:1103-1106.

56 Teng CT: Lactoferrin gene expression and regulation: an overview. Biochem Cell Biol 2002;80:7-16.

57 Haig D: Placental growth hormone-related proteins and prolactin-related proteins. Placenta 2008;29 Suppl A:S36-41.

\$58 Cao J, Gowri PM, Ganguly TC, Wood M, Hyde JF, Talamantes F, Vore M: PRL, placental lactogen, and GH induce $\mathrm{NA}(+)$ /taurocholate-cotransporting polypeptide gene expression by activating signal transducer and activator of transcription-5 in liver cells. Endocrinology 2001;142:4212-4222.

59 Zheng J, Ather JL, Sonstegard TS, Kerr DE: Characterization of the infection-responsive bovine lactoferrin promoter. Gene 2005;353:107-117.

-60 Wang SR, Lin J, Cheng IC, Lin TY: Characterization and functional analysis of the porcine lactoferrin gene promoter. Gene 1998;215:203-212.

61 Journe F, Laurent G, Chaboteaux C, Nonclercq D, Durbecq V, Larsimont D, Body JJ: Farnesol, a mevalonate pathway intermediate, stimulates MCF-7 breast cancer cell growth through farnesoid-X-receptor-mediated estrogen receptor activation. Breast Cancer Res Treat 2008;107:49-61.

62 Goh VJ, Silver DL: The lipid droplet as a potential therapeutic target in NAFLD. Semin Liver Dis 2013;33:312-320.

63 Rohlmann A, Gotthardt M, Hammer RE, Herz J: Inducible inactivation of hepatic LRP gene by cre-mediated recombination confirms role of LRP in clearance of chylomicron remnants. J Clin Invest 1998;101:689-695.

64 Zeng BJ, Mortimer BC, Martins IJ, Seydel U, Redgrave TG: Chylomicron remnant uptake is regulated by the expression and function of heparan sulfate proteoglycan in hepatocytes. J Lipid Res 1998;39:845-860. 